\title{
INFLUENCES OF HILLSLOPE WETNESS CONDITIONS ON THE TEMPORAL STABILITY OF SOIL MOISTURE
}

\author{
LV, L. G. ${ }^{1,2}-$ LIAO, K. H. ${ }^{2 *}-$ LAI, X. M. ${ }^{2}-$ ZHOU, Z. W. ${ }^{2}-$ ZHU, Q. ${ }^{2 *}$ \\ ${ }^{1}$ School of Public Administration, Nanjing University of Finance and Economics \\ Nanjing 210023, China
}

${ }^{2}$ Key Laboratory of Watershed Geographic Sciences, Nanjing Institute of Geography and Limnology, Chinese Academy of Sciences, Nanjing 210008, China

(phone: +86-152-519-52379; fax: +86-25-868-82139)

*Corresponding authors

e-mail:khliao@niglas.ac.cn; qzhu@niglas.ac.cn

(Received 26 $6^{\text {th }}$ Jan 2019; accepted $28^{\text {th }}$ Feb 2019)

\begin{abstract}
Knowledge of soil moisture temporal stability under different wetness conditions is critical for hydrological and environmental management decisions. This study analyzed the soil moisture (mean relative difference, MRD) and its associated temporal stability (standard deviation of the relative difference, SDRD) at two depths $(10$ and $30 \mathrm{~cm})$ during the entire, dry, intermediate and wet periods on a mixed land use (tea garden and forest) hillslope. In addition, the influences of environmental factors on MRD and SDRD were also investigated. Results showed that the MRD of soil moisture had a strong spatial dependence (nugget/sill ratios $<0.25$ ) at each depth during different hillslope wetness periods. The widest range (correlation length) was found during the dry period. In addition, spatial patterns of MRD and SDRD were mainly influenced by topographic factors such as elevation. Correlations between MRD and SDRD were in the order of dry > intermediate > wet conditions. Hillslope wetness conditions had substantial influence on the temporal stability of soil moisture, showing that soil moisture patterns were more stable during wet periods than during dry periods. Therefore, the presentative locations identified with the entire dataset are not always appropriate for estimating hillslope mean soil moisture under all wetness conditions.
\end{abstract}

Keywords: soil texture, temporal variability, geostatistics, environmental factors, regression

Abbreviations: CV, coefficient of variation; DB, depths to bedrock; DEM, digital elevation model; MRD, mean relative difference; PLC, plane curvature; PRC, profile curvature; RF, rock fragment; RMSE, root mean squared error; SDRD, standard deviation of the relative difference; SR, Stepwise regression; TWI, topographic wetness index

\section{Introduction}

Soil moisture is an important variable influencing water and solute fluxes in the earth surface (Vereecken et al., 2007; Feng et al., 2017; Liao et al., 2018a, 2018b). It is a major component of the hydrologic cycle, controlling runoff, infiltration and evapotranspiration processes at various scales (Pachepsky et al., 2003). In addition, soil water movement has substantial influence on nutrient loss and availability (Zhu et al., 2009; Schmidt et al., 2011). Therefore, soil moisture variations are critical in hydrological, ecological and environmental management (Fu et al., 2003; Zhu et al., 2017).

Soil moisture variations were influenced by environmental factors, such as soil properties and topography (Lark, 1999; Qiu et al., 2003; Vereecken et al., 2007; Brocca et al., 2007; Zhu and Lin, 2011). The relationships between environmental factors and soil moisture were often modelled using multiple linear regression (Nyberg, 1996; Qiu et al., 2010; van Arkel, 2012). Some studies have shown that there is a significant 
correlation between soil moisture and environmental factors, while others have indicated that the relationship is insignificant (Famiglietti et al., 1998; Western et al., 1999; Qiu et al., 2001). This may be due to differences in climate, topography, soil, vegetation, scale, time and depth of sampling methods (Famiglietti et al., 1998). The wetness conditions in the study area were also found to affect the relationships between environmental factors and soil moisture content. Previous studies proposed that topography has dominant control on soil moisture distribution under wet soil condition, while soil properties have primary control on soil moisture distribution under dry soil condition (Grayson et al., 1997; Pachepsky et al., 2003; Penna et al., 2013).

Although soil moisture exhibits a high spatio-temporal variability at various scales due to the variations in climate, topography and soil properties, its distribution often shows a similar spatial pattern at different dates (Hu et al., 2010; Penna et al., 2013; Li and Shao, 2014; Qiu et al., 2017). This phenomenon has been called temporal stability by Vachaud et al. (1985), who described it as the time-invariant association between a spatial location and classical statistical parameters. The main purpose of temporal stability analysis of soil moisture was to identify reliable locations that can represent the mean soil moisture content of the entire study area (Grayson and Western, 1998; Jacobs et al., 2004; Zhao et al., 2010).

Relationships between soil moisture temporal stability and environmental factors have often been investigated to identify the best representative locations. Previous studies have found that environmental factors (e.g., soil properties and topography) significantly affected soil water temporal stability (Thierfelder et al., 2003; Vivoni et al., 2008; Brocca et al., 2009; Hu et al., 2010). For example, Vivoni et al. (2008) found that sampling locations with mid elevation tended to have a more pronounced temporal stability. Hu et al. (2010) showed that soil texture can significantly affect the temporal stability of soil water content in the LaoYeManQu watershed, China. In addition, the wetness conditions in the study area had large influence on soil moisture temporal stability. Zhao et al. (2010) observed that the ranked positions of the labelled representative location change with different wetness conditions. This implies that the location with the most pronounced time stability may be different for each wetness condition. Some studies have also demonstrated that soil moisture spatial patterns were more stable during wet periods than during dry periods (Hupet and Vanclooster, 2002; Zhou et al., 2007; Williams et al., 2009; Zhao et al., 2010). This is related to an enhanced capillary movement of water from the subsoil to the topsoil, thereby decreasing temporal stability in topsoil moisture. However, others have shown that a higher degrees of temporal stability in dry conditions than in wet conditions (MartínezFernández and Ceballos, 2003; Lin, 2006; Penna et al., 2013). For example, Lin et al. (2006) found more frequent conditions of marked persistence of soil moisture patterns during a long dry-down period in June. Penna et al. (2013) observed a slightly higher degree of temporal stability in dry conditions and for deeper layers. The mixed results suggest that the effect of wetness status on temporal stability was complex and has not been fully understood.

Therefore, the objectives of this study are to provide a comprehensive investigation on the temporal stability of soil moisture content under different hillslope wetness conditions. For this purpose, a typical mixed land-use (tea garden and forest) hillslope was considered for which soil moisture content at two depths $(0-20$ and 20-40 cm) was repeated measured from January 2013 to December 2015 (a total of 32 sampling days) in 77 sites. The dataset obtained was analyzed for temporal stability analysis. The 
hypotheses of this study are i) the controlling factors of soil moisture and its temporal stability vary with hillslope wetness condition, ii) the temporal stability of soil moisture are different during different hillslope wetness conditions.

\section{Materials and methods}

\section{Study hillslope}

This study was conducted on a hillslope $\left(31^{\circ} 21^{\prime} \mathrm{N}, 119^{\circ} 03^{\prime} \mathrm{E}\right)$ (has an area of $0.6 \mathrm{ha}$ ) in the hilly area of Taihu Lake Basin, China (Fig. 1). This study area is feature with a north subtropical-middle subtropical transition monsoon climate with four distinctive seasons. The annual mean temperature is $15.9^{\circ} \mathrm{C}$ and the annual mean precipitation is $1157 \mathrm{~mm}$. Green tea (Camellia sinensis (L.) O. Kuntze) and Moso bamboo (Phyllostachysedulis (Carr.) H. de Lehaie) are dominant on the hillslope. The elevation of the hillslope ranges from 77 to $88 \mathrm{~m}$ and the slope ranges from 0 to $21 \%$. The soil type of the hillslope is shallow lithosols according to the FAO soil classification (Orthents according to Soil Taxonomy). Parent material is quartz sandstone. Soils are described as silt loam texture with silt content $>60 \%$. Surface $(0-20 \mathrm{~cm})$ soil organic matter contents were about $2 \%$ on both hillslopes. The depth to bedrock varies from $<0.3 \mathrm{~m}$ at the summit slope position to about $1.0 \mathrm{~m}$ at the foot slope position (Liao et al., 2016).

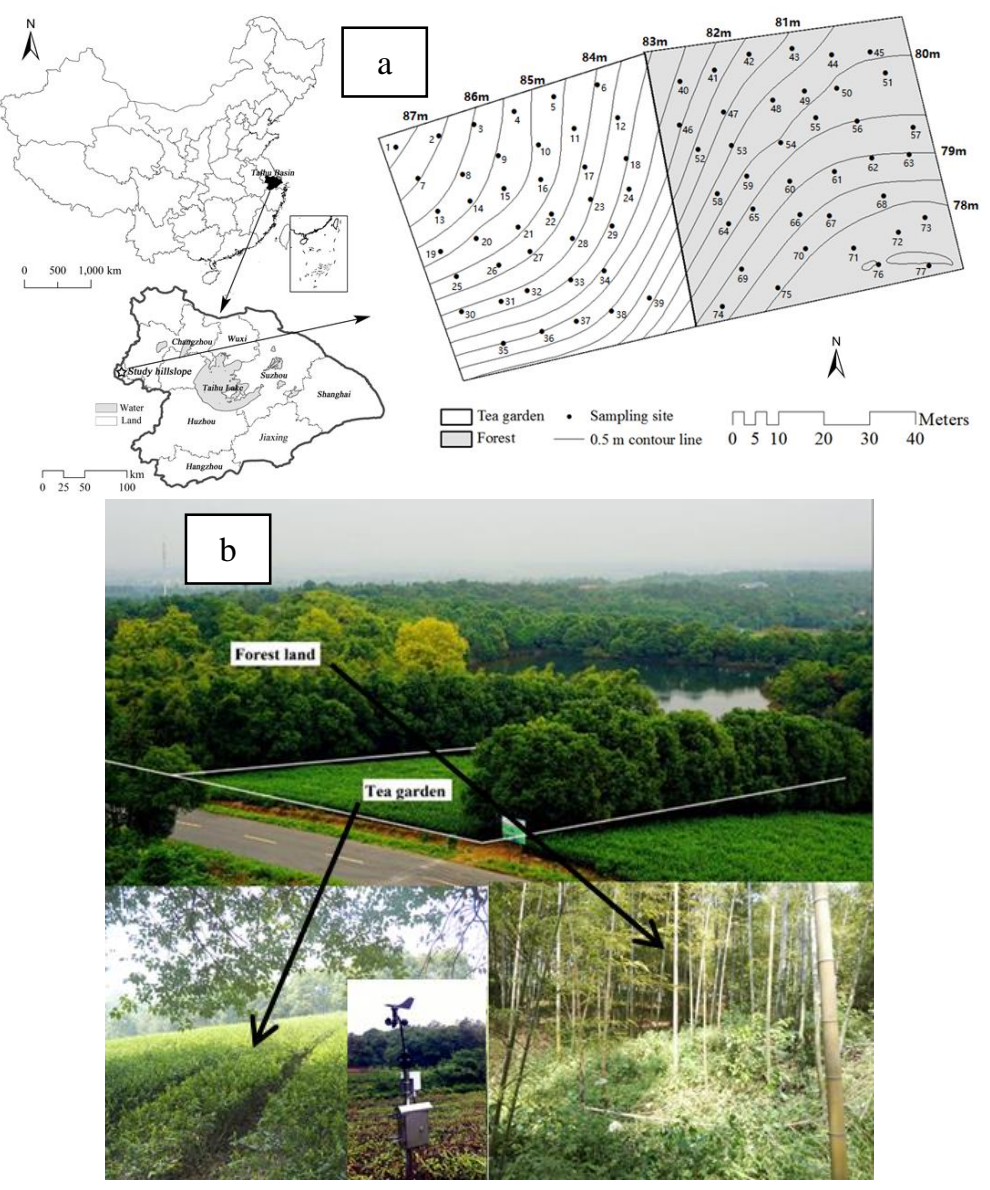

Figure 1. (a) Location of the study area and sampling sites on study hillslope and (b) photographs from the hillslope 


\section{Soil moisture measurement}

For monitoring volumetric soil water content, access polyvinyl chloride tubes were installed at 77 sites on the hillslope (Fig. 1). A portable time-domain reflectrometry TRIME-PICO-IPH soil moisture probe (IMKO, Ettlingen, Germany) was used at 32 dates from January 2013 to December 2015. Volumetric soil water was measured at the depths of 0 to $20 \mathrm{~cm}$ (denoted as $10 \mathrm{~cm}$ ) and 20 to $40 \mathrm{~cm}$ (denoted as $30 \mathrm{~cm}$ ) each time (note that the TRIME-PICO-IPH probe has a length of $18 \mathrm{~cm}$ ). Due to the shallow soil depths at some locations, only 73 sites had soil moisture readings at $30 \mathrm{~cm}$ depth. For each site, the TRIME-PICO-IPH probe was twisted in the access tube to face different directions and 2-3 readings were then taken. The average of these readings was used as the final water content for each site on a specific date. In addition, an outdoor mini weather station was set up to measure rainfall and air temperature. The amounts of precipitation were $889.5 \mathrm{~mm}, 1296.4 \mathrm{~mm}$ and $1617.0 \mathrm{~mm}$ in year 2015, 2016 and 2017, respectively.

\section{Soil properties and terrain attributes}

Around each soil moisture access tube (within 1-m distance), soil samples at each depth interval were collected using a hand auger. Three subsamples were collected for each site and then fully mixed. These samples were air dried, weighted, ground and sieved through a $2 \mathrm{~mm}$ polyethylene sieve. Particles larger than $2 \mathrm{~mm}$ (rock fragments) were weighed to determine the rock fragment (RF) content. Soils that passed through the $2 \mathrm{~mm}$ polyethylene sieve were used to analyze the particle size distribution using the Malvern Mastersizer 2000 laser analyzer (Malvern Instruments Inc., Worcestershire, UK). The fractions of $<0.002 \mathrm{~mm}$ (clay), $0.002-0.05 \mathrm{~mm}$ (silt), and 0.05-2 mm (sand) were determined for each soil sample. The percentage of the organic matter in the soil was measured by the titration method, which is based on the oxidation of organic matter by $\mathrm{K}_{2} \mathrm{Cr}_{2} \mathrm{O}_{7}$. In addition, the depths to bedrock (DB) of all 77 sites were also determined when installing the access tubes for soil moisture measurements and taking soil samples using a hand auger.

A high-resolution $(1 \mathrm{~m})$ digital elevation model (DEM) of the study hillslopes was derived from a 1: 1000 contour map. Terrain attributes including elevation, slope, plane curvature (PLC), profile curvature (PRC), and topographic wetness index (TWI) were determined from this DEM in ArcGIS 10.0 (ESRI, Redlands, CA).

\section{Temporal stability analysis}

The temporal stability of soil water content for each soil depth was analyzed using the approach proposed by Vachaud et al. (1985):

$$
\begin{gathered}
\theta_{j}=\frac{1}{N} \sum_{i=1}^{N} \theta_{i j} \\
\delta_{i j}=\frac{\theta_{i j}-\theta_{j}}{\theta_{j}} \\
M R D=\frac{1}{M} \sum_{j=1}^{M} \delta_{i j}
\end{gathered}
$$




$$
S D R D=\sqrt{\frac{1}{M-1} \sum_{j=1}^{M}\left(\delta_{i j}-M R D\right)^{2}}
$$

where $\theta_{i j}$ is the soil water content at location $i$ in day $j ; \theta_{j}$ is the arithmetic mean of soil water content in day $j ; N$ is the number of locations; $\delta_{i j}$ is the relative difference of soil water content at location $i$ and day $j$; and $M$ is the number of sampling days, in this case, $M=17$. MRD is the arithmetic mean relative difference of soil water content at location $i$; SDRD is the standard deviation of relative difference. The SDRD is the temporal stability of soil water at location $i$. Smaller SDRD means temporally more stable.

\section{Classical statistics}

First soil moisture, soil properties and terrain attributes were investigated using univariate descriptive analysis. The spatial mean soil moisture and corresponding coefficient of variation (CV) were calculated. Correlation analysis was conducted to investigate the relationships between soil moisture contents under different wetness conditions. Stepwise regression (SR) analysis was then conducted to investigate the relationships between environmental factors (e.g., soil properties and topography) and soil moisture and its temporal stability. A backward method regression (Norusis, 1994) was selected and the level for entry in the regression model was set at $p<0.10$, while a 0.05 significance level was applied to retain the variables in the model. In addition, the $t$-test was used to test the significant of differences in SDRD among different wetness conditions.

Dominance analysis was used to quantify the relative influence of soil properties and topography on MRD and SDRD. Budescu (1993) defined dominance as a pairwise relationship that can be tested for all pairs of variables included in the model. Given a single dependent variable $(y)$ and $k$ explanatory variables $\left(x_{1}, x_{2}, \ldots, x_{k}\right)$ (determined by SR analysis), the independent effect of predictor $x_{1}\left(I_{x 1}\right)$ denotes the average contribution of variable $x_{1}$ to the variance in $y$ over all $2^{k}-1$ possible submodels. The independent effect of each variable is computed by comparing the fit of all models containing a particular variable to the fit of all nested models lacking that variable, through the process of hierarchical partitioning. Thus, for variable $x_{1}$,

$$
I_{x_{1}}=\sum_{i=0}^{k-1} \frac{\sum\left(R_{y, x_{1} x_{h}}^{2}-R_{y, x_{h}}^{2}\right) /\left(\begin{array}{c}
k-1 \\
i
\end{array}\right)}{k}
$$

where $x_{h}$ is any subset of $i$ predictors, $x_{1}$ excluded; $R^{2}$ is the coefficient of determination. Because dominance analysis utilizes an all possible models approach, it provides a more robust assessment of variable importance, relative to single-model approaches, by assuring that the contribution of a particular variable is neither enhanced nor masked through its correlation with other explanatory variables (Murray and Conner, 2009). All classical statistics were conducted using the regress function of MATLAB software (The MathWorks Inc., USA) and SPSS statistics 17.0 (SPSS Inc., Chicago, IL, USA).

\section{Geostatistics}

The spatial dependence of soil moisture content was analyzed using semivariograms $\gamma$, which were calculated as follows: 


$$
\gamma(\mathrm{h})=\frac{1}{2 \mathrm{~N}(\mathrm{~h})} \sum_{\mathrm{i}=1}^{\mathrm{N}(\mathrm{h})}\left[\mathrm{Z}_{\mathrm{i}}-\mathrm{Z}_{\mathrm{i}+\mathrm{h}}\right]^{2}
$$

where $N(h)$ is the number of distance pairs within a given distance class, $Z_{\mathrm{i}}$ is the measured variable at location $i$ and $Z_{\mathrm{i}+\mathrm{h}}$ is the variable at locations separated from $i$ by the distance $h$ that fall within the distance class (Yates and Warrick, 1987). Four semivariogram models (spherical, exponential, linear and Gaussian) were used to describe the semivariograms and the best-fitted models with the largest coefficient of determination $\left(R^{2}\right)$ were selected. Then the geostatistical parameters were obtained, including nugget, sill and effective range. The ratio between nugget and sill was used to characterize the spatial dependencies of soil water content. Smaller nugget/sill ratio indicates stronger spatial dependency. All the geostatistical computations were conducted using GS+ 7.0 (Gamma Design Software LLC., Plainwell, MI, USA).

\section{Results and discussion}

\section{Temporal variations of hillslope wetness conditions}

From January 2013 to December 2015, a substantial fluctuation of the hillslope mean soil water content was observed for each depth (Fig. 2). This fluctuation was influenced by climate factors, such as precipitation and evapotranspiration.

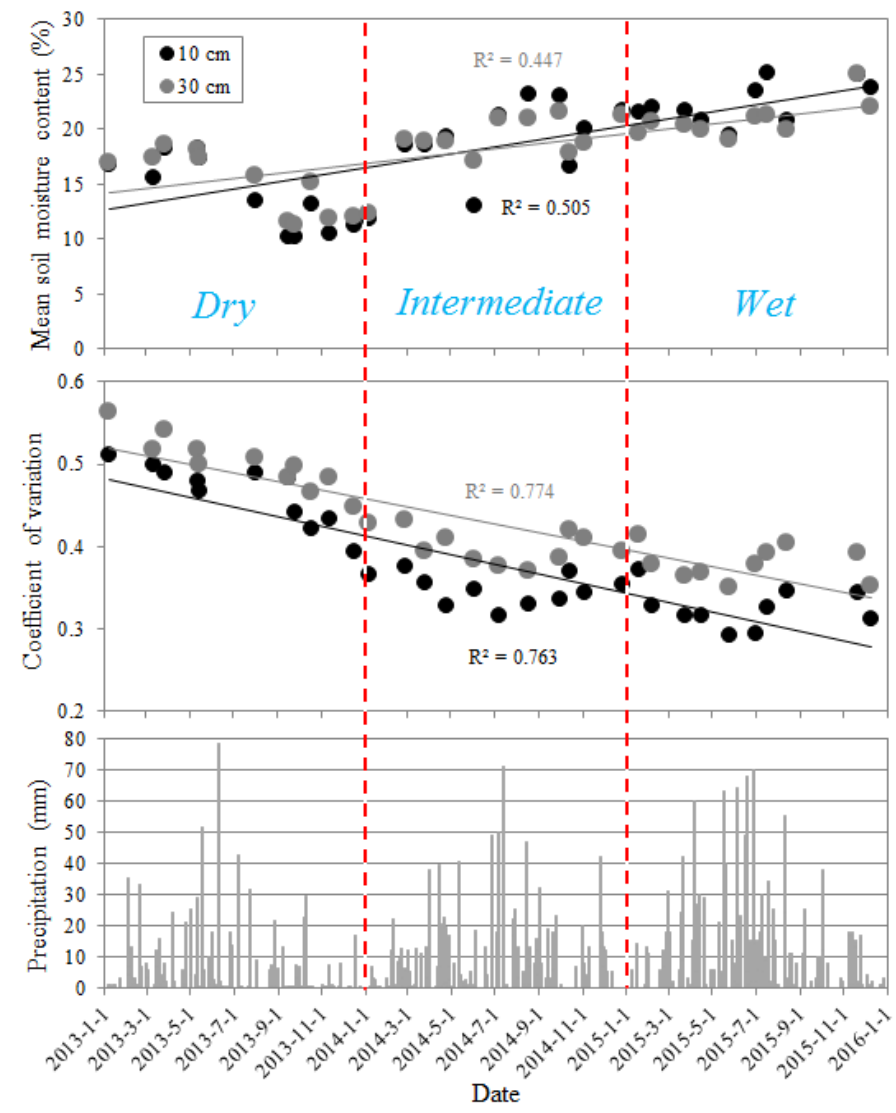

Figure 2. Time series of precipitation, average soil water contents and corresponding coefficients of variation at two depths 
The mean soil moisture contents of were $10.18-25.15 \%$ and $11.24-24.90 \%$ at 10 - and $30-\mathrm{cm}$ depths, respectively. An increasing trend of mean soil moisture with time was found at two depths, which can be fitted by a linear function $\left(\mathrm{R}^{2}=0.505\right.$ for $10 \mathrm{~cm}$ $(\mathrm{P}<0.01)$ and $\mathrm{R}^{2}=0.447$ for $\left.30 \mathrm{~cm}(\mathrm{P}<0.01)\right)$. The reason is that the amount of precipitation increased yearly $(890.5,1296.4$ and $1617.0 \mathrm{~mm}$ for the year 2013, 2014 and 2015, respectively). Therefore, hillslope wetness conditions can be classified as dry, intermediate and wet periods, corresponding to year 2013, 2014 and 2015, respectively. The mean soil moisture contents were $14.10,18.82$ and $22.38 \%$ at $10 \mathrm{~cm}$ depth during dry, intermediate and wet periods, respectively, while these values were 15.06, 18.82 and $20.85 \%$ at $30 \mathrm{~cm}$ depth during dry, intermediate and wet periods respectively (Table 1). In addition, seasonal patterns of mean soil moisture were similar from one year to the next year. The highest mean soil moisture content was observed in summer season (from July to September) due to intense and heavy rainfalls occurred, while the lowest value was measured in winter and spring seasons (from November to March) due to the relatively low precipitation.

Table 1. Statistics of soil moisture at two depths under different hillslope wetness conditions

\begin{tabular}{c|c|c|c|c|c|c}
\hline & \multicolumn{3}{|c|}{$\mathbf{1 0} \mathbf{~ c m}$} & \multicolumn{3}{c}{$\mathbf{3 0} \mathbf{~ c m}$} \\
\cline { 2 - 7 } & Dry & Intermediate & Wet & Dry & Intermediate & Wet \\
\hline No. of locations & 77 & 77 & 77 & 73 & 73 & 73 \\
No. of sampling times & 11 & 11 & 10 & 11 & 11 & 10 \\
No. of measurements & 847 & 847 & 770 & 803 & 803 & 730 \\
Mean (\%) & 14.10 & 18.82 & 22.38 & 15.06 & 18.82 & 20.85 \\
SD (\%) & 3.29 & 3.73 & 1.91 & 2.85 & 2.63 & 1.66 \\
CV & 0.23 & 0.20 & 0.09 & 0.19 & 0.14 & 0.08 \\
\hline
\end{tabular}

SD: standard deviation; CV: coefficient of variation

The corresponding CV values were $0.293-0.510$ and $0.351-0.562$ at $10-$ and $30-\mathrm{cm}$ depths, respectively (Fig. 2). The soil moisture at $30 \mathrm{~cm}$ depth was found to have stronger variability than that at $10 \mathrm{~cm}$ depth. Temporal series of $\mathrm{CV}$ for each depth can also be fitted by a linear function $\left(\mathrm{R}^{2}=0.763\right.$ for $10 \mathrm{~cm}(\mathrm{P}<0.01)$ and $\mathrm{R}^{2}=0.774$ for $30 \mathrm{~cm}(\mathrm{P}<0.01))$. The temporal variations of $\mathrm{CV}$ showed the opposite trend as compared to those of the mean soil moisture for each depth (Fig. 2). This suggests that the spatial heterogeneity of soil moisture content increases as the soil gets drier. Previous studies also found an increase in spatial variability with decreasing mean soil moisture (Famiglietti et al., 1999; Choi and Jacobs, 2010; Brocca et al., 2012; Korres et al., 2015).

\section{Influencing factors of MRD}

At $10 \mathrm{~cm}$ depth, the MRD of soil moisture content was mainly influenced by elevation, PLC, DB and RF during the entire period, while at $30 \mathrm{~cm}$ depth, it was affected by elevation, PRC, DB, RF and Sand (Table 2). Negative coefficients for elevation, PLC, RF and sand and positive coefficients for other factors were observed, indicating that elevation, PLC, RF and sand were significantly $(\mathrm{P}<0.05)$ negatively correlated with soil moisture, whereas $\mathrm{PRC}$ and $\mathrm{DB}$ were significantly $(\mathrm{P}<0.05)$ positively correlated with soil moisture. The results are consistent with previous studies (Tromp-van Meerveld and McDonnell, 2006; Brocca et al., 2007; McMillan and Srinivasan, 2015). The $\mathrm{R}^{2}$ values of stepwise regression models were 0.649 and 0.643 at 
10 and $30 \mathrm{~cm}$ depths, respectively. This suggests that environmental factors can explain nearly $65 \%$ of variation in soil moisture at each depth. The accuracies of soil moisture predictions in our study were comparable with those reported by previous studies (Western et al., 1999; Qiu et al., 2010). The importance of the variables was sequenced as elevation $>\mathrm{DB}>\mathrm{PLC}>\mathrm{RF}$ according to standardized regression coefficients at $10 \mathrm{~cm}$ depth (Table 2). However, the $I$ values for elevation, PLC, DB and RF were 0.373, $0.040,0.120$ and 0.116 , respectively (Table 3 ). This indicates that elevation is the most important variable, while PLC is the least important variable among the four variables. This suggests that the use of standardized regression coefficients would result in wrong conclusions regarding the relative importance of the variables influencing soil moisture variations.

Table 2. Results of stepwise regression analysis for environmental factors versus mean relative difference

\begin{tabular}{|c|c|c|c|c|c|c|c|c|}
\hline \multirow{2}{*}{$\begin{array}{c}\text { Hillslope } \\
\text { moisture status }\end{array}$} & \multicolumn{4}{|c|}{$10 \mathrm{~cm}$} & \multicolumn{4}{|c|}{$30 \mathrm{~cm}$} \\
\hline & Variables & Coefficients & SC & $I$ & Variables & Coefficients & SC & $I$ \\
\hline \multirow[t]{7}{*}{ Entire period } & Constant & 6.068 & & & Constant & 5.431 & & \\
\hline & Elevation & -0.075 & -0.565 & 0.373 & Elevation & -0.064 & -0.434 & 0.267 \\
\hline & PLC & -0.018 & -0.177 & 0.040 & PRC & 0.017 & 0.205 & 0.108 \\
\hline & DB & 0.006 & 0.228 & 0.120 & DB & 0.006 & 0.191 & 0.083 \\
\hline & $\mathrm{RF}$ & -0.006 & -0.170 & 0.116 & $\mathrm{RF}$ & -0.007 & -0.205 & 0.076 \\
\hline & $R^{2}$ & 0.649 & & & Sand & -0.016 & -0.180 & 0.109 \\
\hline & & & & & $R^{2}$ & 0.643 & & \\
\hline \multirow[t]{7}{*}{ Dry } & Constant & 7.051 & & & Constant & 6.446 & & \\
\hline & Elevation & -0.086 & -0.528 & 0.349 & Elevation & -0.076 & -0.425 & 0.276 \\
\hline & PLC & -0.019 & -0.149 & 0.036 & PLC & -0.025 & -0.182 & 0.104 \\
\hline & DB & 0.008 & 0.231 & 0.107 & DB & 0.007 & 0.192 & 0.079 \\
\hline & $\mathrm{RF}$ & -0.009 & -0.201 & 0.126 & $\mathrm{RF}$ & -0.008 & -0.180 & 0.073 \\
\hline & $R^{2}$ & 0.618 & & & Sand & -0.024 & -0.224 & 0.112 \\
\hline & & & & & $R^{2}$ & 0.644 & & \\
\hline \multirow[t]{7}{*}{ Intermediate } & Constant & 5.730 & & & Constant & 4.766 & & \\
\hline & Elevation & -0.074 & -0.613 & 0.387 & Elevation & -0.056 & -0.405 & 0.237 \\
\hline & PLC & -0.018 & -0.193 & 0.118 & PRC & 0.017 & 0.223 & 0.112 \\
\hline & DB & 0.006 & 0.260 & 0.110 & DB & 0.006 & 0.195 & 0.078 \\
\hline & $R^{2}$ & 0.615 & & & $\mathrm{RF}$ & -0.006 & -0.180 & 0.102 \\
\hline & & & & & Sand & -0.016 & -0.191 & 0.077 \\
\hline & & & & & $R^{2}$ & 0.606 & & \\
\hline \multirow[t]{6}{*}{ Wet } & Constant & 7.114 & & & Constant & 5.073 & & \\
\hline & Elevation & -0.085 & -0.725 & 0.343 & Elevation & -0.061 & -0.456 & 0.255 \\
\hline & PLC & -0.033 & -0.370 & 0.132 & PRC & 0.017 & 0.226 & 0.120 \\
\hline & PRC & -0.017 & -0.266 & 0.083 & DB & 0.006 & 0.194 & 0.074 \\
\hline & Sand & -0.015 & -0.244 & 0.098 & $\mathrm{RF}$ & -0.009 & -0.272 & 0.132 \\
\hline & $R^{2}$ & 0.656 & & & $R^{2}$ & 0.581 & & \\
\hline
\end{tabular}

SC: standardized coefficient; I: independent effect; PLC: plane curvature; DB: depth to bedrock; RF: rock fragment; PRC: profile curvature

The factors influencing the MRD of soil moisture content were slightly different for each period at both depths (Table 2). However, topography was always found to explain more variability $(49.2-61.5 \%$ for $10 \mathrm{~cm}$ and $42.7-45.9 \%$ for $30 \mathrm{~cm})$ in soil moisture than soil properties $(0-12.6 \%$ for $10 \mathrm{~cm}$ and $13.2-18.5 \%$ for $30 \mathrm{~cm})$ under different hillslope wetness conditions. Our results are not consistent with previous studies that indicated a larger influence of soil properties than topography on soil moisture under dry conditions 
(Grayson et al., 1997; Pachepsky et al., 2003; Penna et al., 2013) or wet (Laio et al., 2002; Baroni et al., 2013) conditions. This may be related to relatively homogeneous soil properties on study hillslope.

Table 3. Influence of environmental factors on mean relative difference at 10-cm depth during the entire period by using dominance analysis

\begin{tabular}{c|c|c|c|c|c}
\hline \multirow{2}{*}{ Submodels } & \multirow{2}{*}{$\mathbf{R}^{\mathbf{2}}$} & \multicolumn{4}{|c}{ Increase in $\mathbf{R}^{\mathbf{2}}$} \\
\cline { 3 - 6 } & & $\mathbf{E}$ & PLC & DB & RF \\
\hline Contribution $(k=0)$ & 0 & 0.550 & 0.049 & 0.225 & 0.238 \\
E & 0.550 & - & 0.024 & 0.051 & 0.025 \\
PLC & 0.049 & 0.525 & - & 0.224 & 0.247 \\
DB & 0.225 & 0.376 & 0.048 & - & 0.142 \\
RF & 0.238 & 0.337 & 0.058 & 0.129 & - \\
Contribution $(k=1)$ & - & 0.413 & 0.043 & 0.135 & 0.138 \\
E+PLC & 0.574 & - & - & 0.053 & 0.030 \\
E+DB & 0.601 & - & 0.026 & - & 0.017 \\
E+RF & 0.575 & - & 0.029 & 0.043 & - \\
PLC+DB & 0.273 & 0.354 & - & - & 0.150 \\
PLC+RF & 0.296 & 0.308 & - & 0.127 & - \\
DB+RF & 0.367 & 0.251 & 0.056 & - & - \\
Contribution $(k=2)$ & - & 0.304 & 0.037 & 0.074 & 0.066 \\
E+PLC+DB & 0.627 & - & - & - & 0.022 \\
E+PLC+RF & 0.604 & - & - & 0.045 & - \\
E+DB+RF & 0.618 & - & 0.031 & - & - \\
PLC+DB+RF & 0.423 & 0.226 & - & - & - \\
Contribution $(k=3)$ & - & 0.226 & 0.031 & 0.045 & 0.022 \\
E+PLC+DB+RF & 0.649 & - & - & - & - \\
Independent effect $(I)$ & - & 0.373 & 0.040 & 0.120 & 0.116 \\
Standardized coefficient & - & -0.505 & -0.177 & 0.228 & -0.170 \\
\hline E & - & - &
\end{tabular}

E: elevation; PLC: plane curvature; DB: depth to bedrock; RF: rock fragment

\section{Spatial patterns of MRD}

The MRD dataset under different hillslope wetness conditions had low skewness (0.181-0.383) and kurtosis (-0.620--0.145), thus meeting the requirement of a normal distribution for kriging prediction. The semivariogram of MRD provided a clear description of its spatial structure with some insight into possible processes influencing its spatial distribution (Table 4). The semivariograms of MRD at $10 \mathrm{~cm}$ depth were well fitted with the spherical and Gaussian model under the entire and wet periods, respectively, whereas the remaining semivariograms were well fitted with an exponential model. The nugget/sill ratios of the fitted semivariogram models for MRD under different wetness conditions were less than 0.25 , indicating that soil moisture had a strong spatial dependence on study hillslope. Range can reflect some information about spatial dependency of environmental variables (Wu et al., 2009). The semivariogram of MRD had 95.1-115.8 $\mathrm{m}$ of range at $10 \mathrm{~cm}$ depth, while the semivariogram of MRD had 38.7-62.1 $\mathrm{m}$ of range at $30 \mathrm{~cm}$ depth. This means that soil moisture at $10 \mathrm{~cm}$ depth had stronger spatial structure than at $30 \mathrm{~cm}$ depth. In addition, for each depth, the largest range was found during the dry period. This is related to the fact that when soil is dry the soil moisture is relative uniform (Lv et al., 2016). 
Table 4. Semivariance analysis of mean relative difference at two depths under different hillslope wetness conditions

\begin{tabular}{c|c|c|c|c|c|c}
\hline Variable & Model & Nugget & Sill & Nugget/sill ratio & Range (m) & $\mathbf{R}^{\mathbf{2}}$ \\
\hline MRD-10cm-Entire & $\mathrm{S}$ & 0.018 & 0.138 & 0.130 & 84.7 & 0.900 \\
MRD-10cm-Dry & $\mathrm{E}$ & 0.014 & 0.223 & 0.061 & 115.8 & 0.865 \\
MRD-10cm-Intermediate & $\mathrm{E}$ & 0.002 & 0.115 & 0.016 & 95.1 & 0.878 \\
MRD-10cm-Wet & $\mathrm{G}$ & 0.033 & 0.161 & 0.202 & 109.5 & 0.955 \\
MRD-30cm-Entire & $\mathrm{E}$ & 0.000 & 0.133 & 0.001 & 46.8 & 0.795 \\
MRD-30cm-Dry & $\mathrm{E}$ & 0.008 & 0.212 & 0.035 & 62.1 & 0.747 \\
MRD-30cm-Intermediate & $\mathrm{E}$ & 0.000 & 0.119 & 0.001 & 38.7 & 0.798 \\
MRD-30cm-Wet & $\mathrm{E}$ & 0.000 & 0.111 & 0.001 & 42.0 & 0.892 \\
\hline
\end{tabular}

S-spherical model; E-exponential model; G-Gaussian model

From the maps of predicted MRD developed by kriging (Fig. 3), we found that the MRD had strong spatial variability on study hillslope.
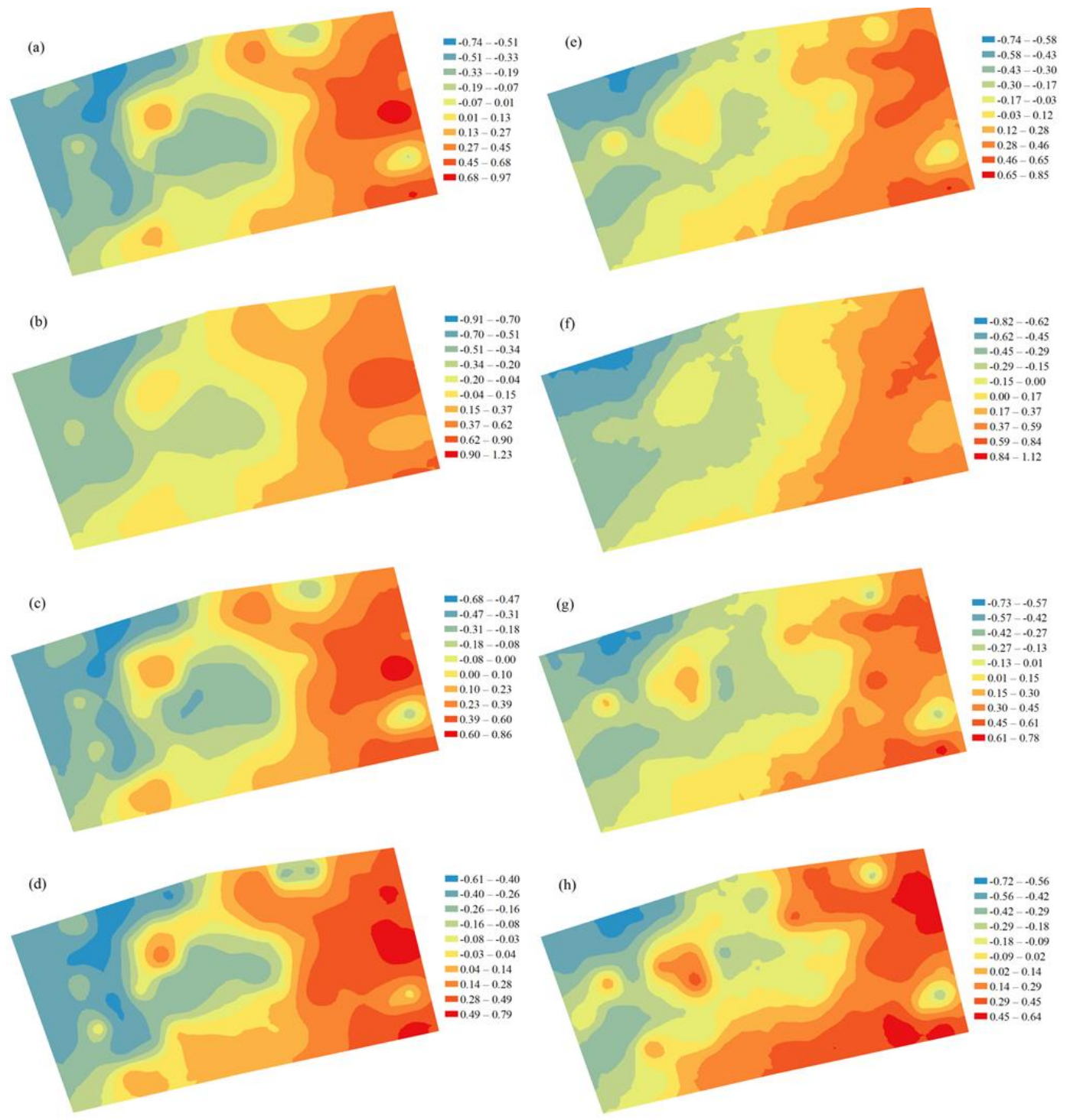

Figure 3. Spatial distribution of mean relative difference at depths of $10(a-d)$ and $30 \mathrm{~cm}(e-h)$ during the entire $(a, e)$, dry $(b, f)$, intermediate $(c, g)$ and wet $(d, h)$ periods 
The MRD values in the northwestern region of the study hillslope were generally lower, whereas the MRD values in the southeastern region were generally higher. Spatial patterns of MRD were similar to that of elevation (Fig. 1). This suggests that elevation had large influence on soil moisture variations, which is consistent with the results of stepwise regression (Table 2). In addition, the distributions of soil moisture presented a similar spatial pattern for each depth under different hillslope wetness conditions. Correlation matrix of MRD is shown in Fig. 4, including all possible combinations, even between different soil depths. Interestingly, all correlation coefficients were larger than 0.7 , indicating the pronounced stability of soil moisture at two depths. Generally, lower values of correlation (but still fully above the statistical significance level, $p<0.01$ ) were associated to comparisons of MRD between two soil depths. In addition, for each depth, the correlation between MRD during wet period and MRD during dry period was weakest among all cases, indicating that soil moisture patterns during dry and wet periods were different to some extent.



Figure 4. Correlation matrix of mean relative differences under different hillslope wetness conditions at two depths

\section{Relationships between MRD and SDRD}

During the entire period, MRD was positively significantly $(\mathrm{P}<0.01)$ correlated to SDRD for each depth (Fig. 5), which implies that the value of SDRD tended to be lower for the drier locations. This is consistent with the results of Martínez-Fernández and Ceballos (2003) and Hu et al. (2010). Correlation coefficients between MRD and SDRD at $10 \mathrm{~cm}$ depth during dry, intermediate and wet periods were $0.659(\mathrm{P}<0.01), 0.468$ $(\mathrm{P}<0.01)$ and $0.320(\mathrm{P}<0.01)$ respectively, while these values at $30 \mathrm{~cm}$ depth during dry, intermediate and wet periods were $0.582(\mathrm{P}<0.01), 0.277(\mathrm{P}<0.05)$ and $0.231(\mathrm{P}<0.05)$, respectively. This indicates that the correlations between MRD and SDRD at each depth were in the order of dry > intermediate $>$ wet conditions. Hillslope wetness conditions had substantial influence on temporal stability of soil moisture. This is different from the finding of Martínez-Fernández and Ceballos (2003) that the amount of rainfall was not seen to modify the patterns of temporal stability. In addition, stronger correlations were found at $10 \mathrm{~cm}$ depth than at $30 \mathrm{~cm}$ depth. This is probably due to stronger variability of soil moisture at $30 \mathrm{~cm}$ depth than that at $10 \mathrm{~cm}$ depth. 

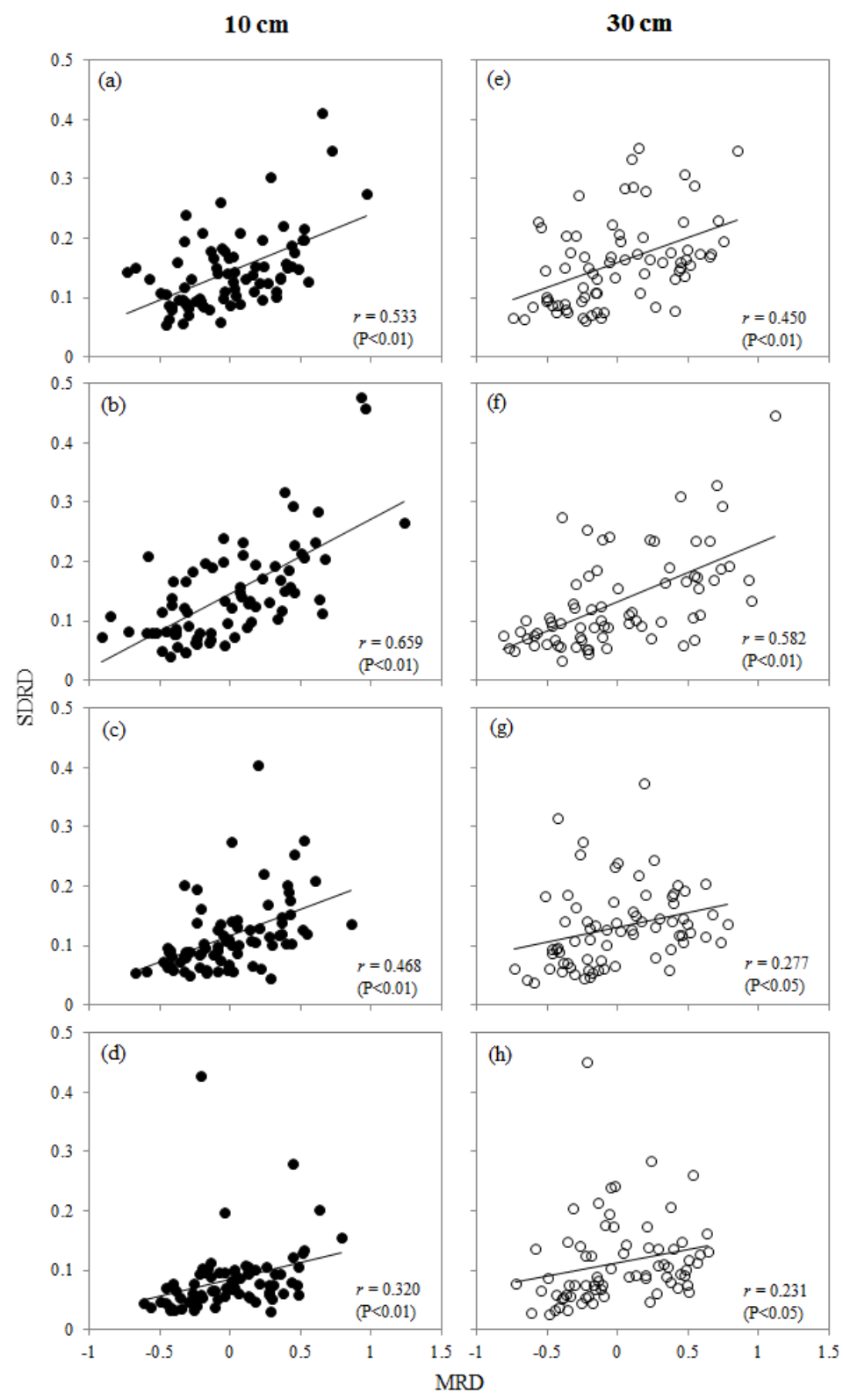

Figure 5. Relationships between mean relative difference and standard deviation of relative difference at depths of $10(a-d)$ and $30 \mathrm{~cm}(e-h)$ during the entire $(a, e)$, dry $(b, f)$, intermediate $(c, g)$ and wet $(d, h)$ periods

From Fig. 6, it can be seen that there is a significant difference $(\mathrm{P}<0.05)$ in hillslope mean SDRD at $10 \mathrm{~cm}$ depth between dry (0.145), intermediate $(0.117)$ and wet $(0.085)$ periods. For $30 \mathrm{~cm}$ depth, hillslope mean SDRD under wet condition (0.112) was significantly less than those under dry (0.133) and intermediate $(0.131)$ conditions. As a result, soil moisture patterns were more stable during wet period than during dry period. This is consistent with most previous studies (Gómez-Plaza et al., 2000; Williams et al., 2009; Zhao et al., 2010; Penna et al., 2013). Conversely, the results by MartínezFernández and Ceballos (2003) and Lin (2006) reveal a constant higher degree of temporal stability during dry conditions. This suggests that relatively homogeneous soil properties favor the temporal persistence of soil moisture patterns in wet conditions. 


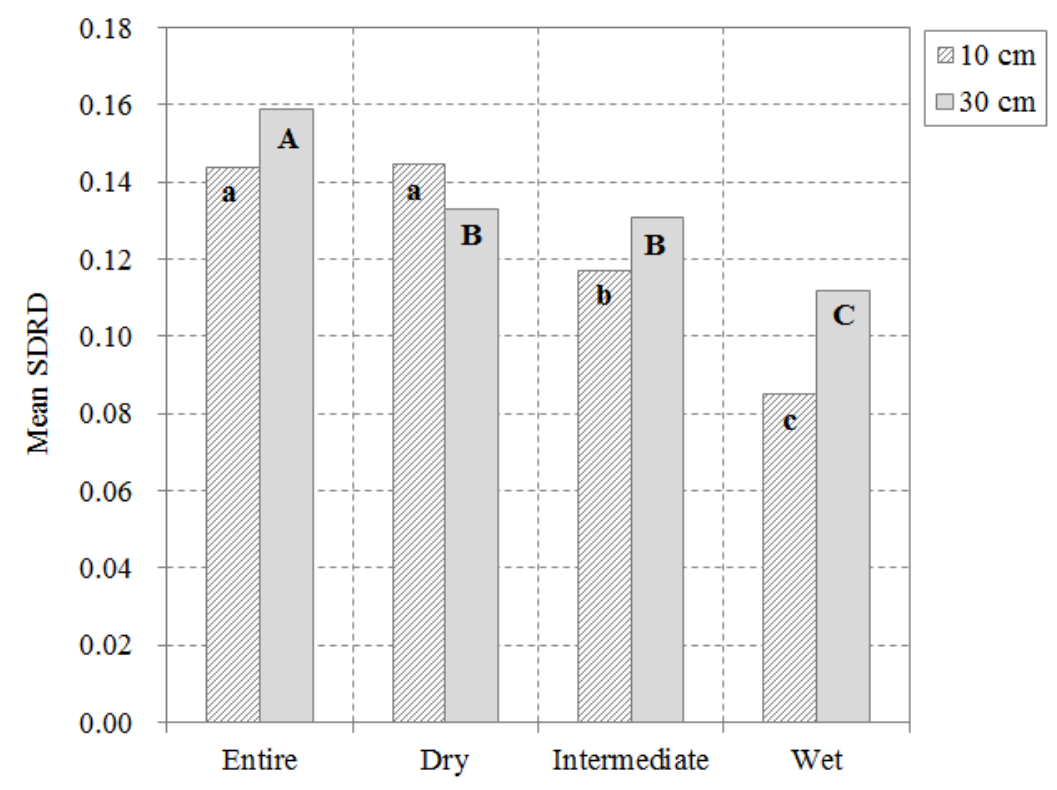

Figure 6. Standard deviation of relative difference at different hillslope wetness conditions. The same lowercase and capital do not show significant difference at $p<0.05$

\section{Identification of representative locations}

The rank ordered MRD and its associated SDRD, as well as locations with absolute MRD less than 5\% and the driest and wettest 10 locations are shown in Fig. 7. Obviously, the rank of MRD varied with soil depth. This is consistent with previous studies (Starks et al., 2006; Hu et al., 2010). During the entire period, locations 4 and 9 can be representative of dry conditions at $10 \mathrm{~cm}$ depth, and locations 77 and 63 of wet conditions. In addition, the absolute MRD of locations 11, 10, 46, 59 22, 54, 12, 65, 53 and 34 were less than $5 \%$ at $10 \mathrm{~cm}$ depth. Among these 10 locations, the SDRD of location 22 was smallest. Therefore, location 22 can directly represent the hillslope mean soil moisture content at $10 \mathrm{~cm}$ depth. Likewise, location 60 can be representative of $30 \mathrm{~cm}$ depth. As can be seen in Fig. 8, there is a close linear regression between the measured moisture contents at the representative locations and the hillslope mean values $\left(R^{2}=0.882\right.$ and root mean squared error $(\mathrm{RMSE})=1.55 \%$ for $10 \mathrm{~cm} ; R^{2}=0.729$ and $\mathrm{RMSE}=2.62 \%$ for $30 \mathrm{~cm}$ ). This indicates that locations 22 and 60 are appropriate for estimating hillslope mean soil moisture with an acceptable degree of accuracy at depths of 10 and $30 \mathrm{~cm}$, respectively, regardless of the hillslope wetness conditions.

At $10 \mathrm{~cm}$ depth, locations 35, 22 and 22 can best represent the hillslope mean soil moisture content under dry, intermediate and wet conditions respectively, while locations 60, 60 and 19 can be representative of $30 \mathrm{~cm}$ depth under dry, intermediate and wet conditions respectively (Fig. 7). This implies that the presentative locations identified with the entire dataset are not always appropriate for estimating hillslope mean soil moisture under all wetness conditions. Therefore, location 22 was replaced by location 35 for predicting hillslope mean soil moisture content at $10 \mathrm{~cm}$ depth under dry period, while location 60 was replaced by location 19 at $30 \mathrm{~cm}$ depth under wet period. It is found that the accuracy of the linear regression was substantially improved after correction $\left(R^{2}=0.926\right.$ and $\mathrm{RMSE}=1.28 \%$ for $10 \mathrm{~cm} ; R^{2}=0.794$ and $\mathrm{RMSE}=1.90 \%$ for $30 \mathrm{~cm})$ (Fig. 8). 


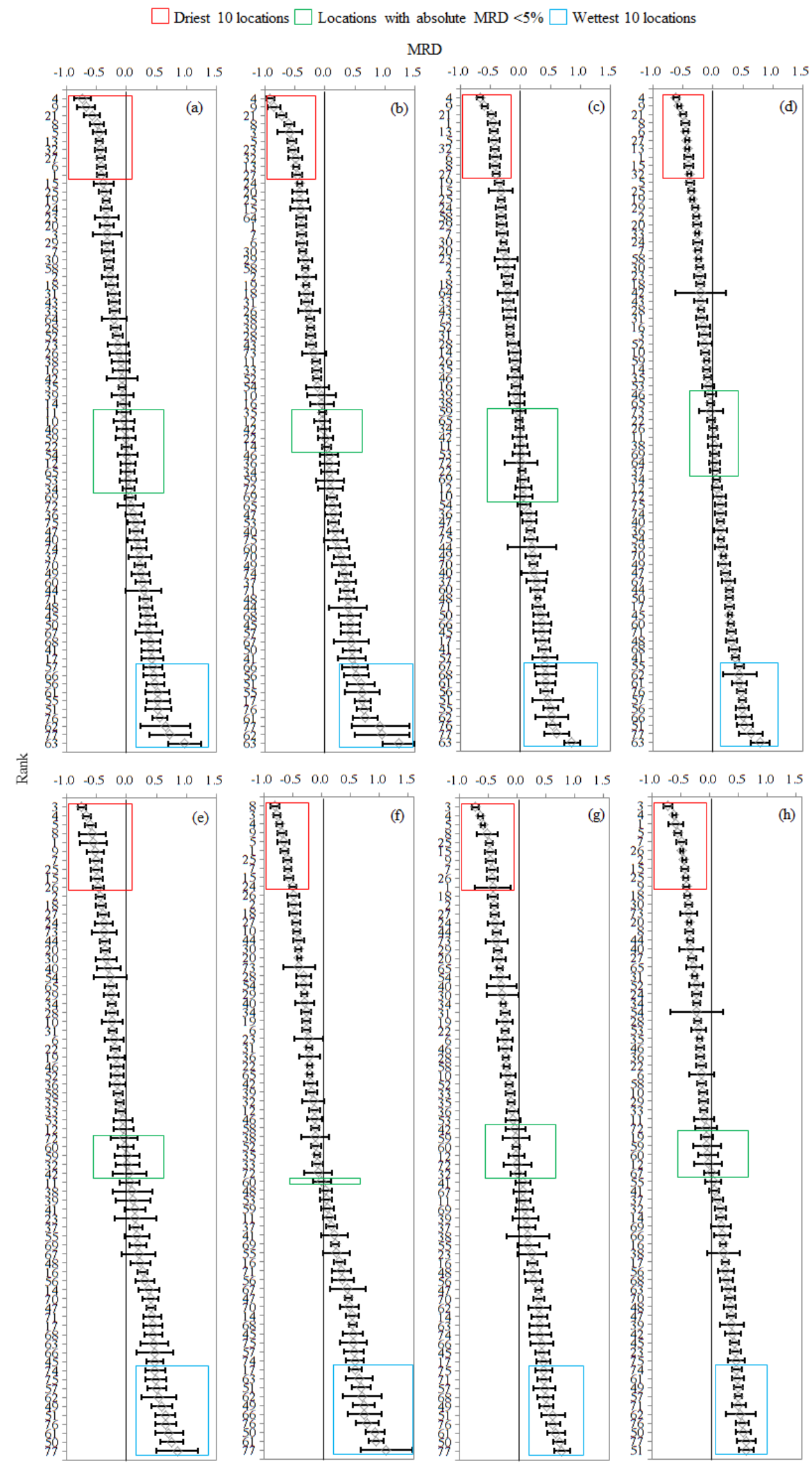

Figure 7. Rank ordered mean relative differences $(M R D)$ at depths of $10(a-d)$ and $30 \mathrm{~cm}(e-h)$ during the entire $(a, e), d r y(b, f)$, intermediate $(c, g)$ and wet $(d, h)$ periods. Vertical bars correspond to \pm standard deviation of the relative difference over time. Sampling locations are presented orderly according to the MRD 

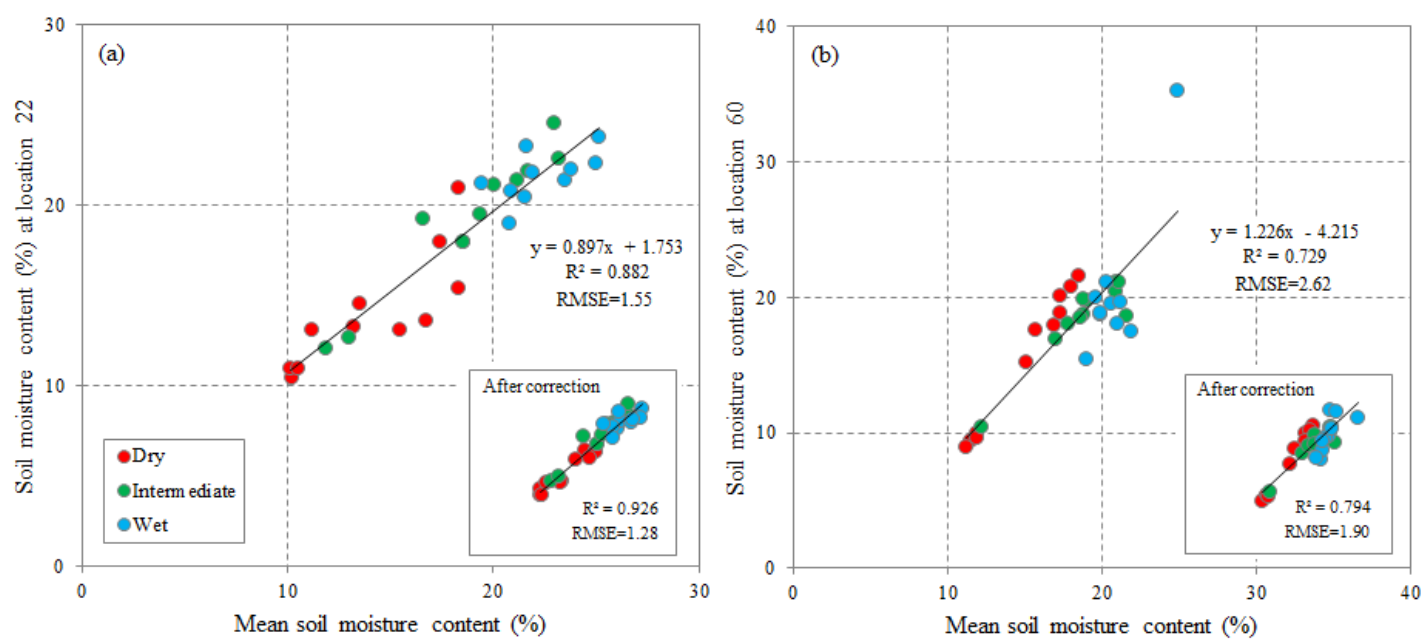

Figure 8. Hillslope mean soil moisture content versus the representative point moisture content at the depths of $10(a)$ and $30 \mathrm{~cm}(b)$. Results after correction (location 22 was replaced by location 35 for predicting hillslope mean soil moisture content at $10 \mathrm{~cm}$ depth under dry period, while location 60 was replaced by location 19 at $30 \mathrm{~cm}$ depth under wet period) are shown in the lower right corner of the figure

\section{Influencing factors of SDRD}

At $10 \mathrm{~cm}$ depth, the SDRD was mainly influenced by PLC, slope and RF during the entire period, while at $30 \mathrm{~cm}$ depth it was affected by only elevation (Table 5). Negative coefficients for all variables were observed, indicating a significant $(\mathrm{P}<0.05)$ negative correlation between these variables and SDRD.

Table 5. Results of stepwise regression analysis for environmental factors versus standard deviation of relative difference

\begin{tabular}{|c|c|c|c|c|c|c|c|c|}
\hline \multirow{2}{*}{$\begin{array}{c}\text { Hillslope moisture } \\
\text { status }\end{array}$} & \multicolumn{4}{|c|}{$10 \mathrm{~cm}$} & \multicolumn{4}{|c|}{$30 \mathrm{~cm}$} \\
\hline & Variables & Coefficients & $\mathrm{SC}$ & $I$ & Variables & oefficients & $\mathrm{SC}$ & $I$ \\
\hline \multirow[t]{5}{*}{ Entire period } & Constant & 0.298 & & & Constant & 1.038 & & \\
\hline & PLC & -0.004 & -0.232 & 0.095 & Elevation & -0.011 & -0.394 & 0.155 \\
\hline & Slope & -0.004 & -0.261 & 0.093 & $R^{2}$ & 0.155 & & \\
\hline & $\mathrm{RF}$ & -0.002 & -0.358 & 0.101 & & & & \\
\hline & $R^{2}$ & 0.289 & & & & & & \\
\hline \multirow[t]{5}{*}{ Dry } & Constant & 0.859 & & & Constant & 1.460 & & \\
\hline & Elevation & -0.006 & -0.207 & 0.092 & Elevation & -0.016 & -0.520 & 0.274 \\
\hline & Slope & -0.007 & -0.336 & 0.175 & Slope & -0.005 & -0.263 & 0.152 \\
\hline & $\mathrm{RF}$ & -0.003 & -0.294 & 0.103 & $R^{2}$ & 0.426 & & \\
\hline & $R^{2}$ & 0.370 & & & & & & \\
\hline \multirow{4}{*}{ Intermediate } & Constant & 0.692 & & & $\mathrm{a}$ & & & \\
\hline & Elevation & -0.007 & -0.283 & 0.103 & & & & \\
\hline & Slope & -0.004 & -0.262 & 0.090 & & & & \\
\hline & $R^{2}$ & 0.193 & & & & & & \\
\hline \multirow[t]{4}{*}{ Wet } & Constant & 0.676 & & & Constant & 0.973 & & \\
\hline & Elevation & -0.007 & -0.343 & 0.117 & Elevation & -0.011 & -0.403 & 0.155 \\
\hline & $R^{2}$ & 0.117 & & & PRC & -0.004 & -0.305 & 0.091 \\
\hline & & & & & $R^{2}$ & 0.246 & & \\
\hline
\end{tabular}

SC: standardized coefficient; I: independent effect; PLC: plane curvature; RF: rock fragment; PRC: profile curvature.

a: No sound stepwise regression model was found 
The $R^{2}$ values of stepwise regression models were 0.289 and 0.155 at 10 and $30 \mathrm{~cm}$ depths, respectively. This suggests that environmental factors can only explain $28.9 \%$ and $15.5 \%$ of variation in SDRD at depths of 10 and $30 \mathrm{~cm}$ depths, respectively, which is comparable to the finding of $\mathrm{Hu}$ et al. (2010). Topography explained more variability $(18.8 \%$ for $10 \mathrm{~cm}$ and $15.5 \%$ for $30 \mathrm{~cm})$ in SDRD than soil properties $(10.1 \%$ for $10 \mathrm{~cm}$ and 0 for $30 \mathrm{~cm}$ ). Therefore, topography had dominant control on soil moisture temporal stability on study hillslope. This is consistent with the study by Grayson and Western (1998) and Vivoni et al. (2008).

The $R^{2}$ of regression equations for SDRD at $10 \mathrm{~cm}$ depth were $0.370,0.193$ and 0.117 under dry, intermediate and wet periods, respectively. This indicates that environmental factors can explain the most variability (37.0\%) in SDRD during the dry period. This may be attributed to the fact that the strongest correlation between MRD and SDRD was found during the dry period. Similarly, topography can explain the most variability (42.6\%) in SDRD at $30 \mathrm{~cm}$ depth during the dry period. However, topography did not significantly affect the SDRD during the intermediate period. This may be attributed to the relatively weak correlation between MRD and SDRD at $30 \mathrm{~cm}$ depth during this period. Overall, hillslope wetness conditions can modify the effects of environmental factors on temporal stability.

\section{Conclusions}

Topography had larger influence on soil moisture content denoted as MRD than soil properties at each depth under different hillslope wetness conditions. The MRD of Soil moisture had a strong spatial dependence on study hillslope. However, soil moisture at $10 \mathrm{~cm}$ depth had stronger spatial structure than at $30 \mathrm{~cm}$ depth in terms of effective range. In addition, for each depth, the largest effective range was found during the dry period.

The value of SDRD tended to be lower for the drier locations. Correlations between MRD and SDRD at each depth were in the order of dry > intermediate > wet conditions. Therefore, hillslope wetness conditions had substantial influence on temporal stability of soil moisture. Soil moisture patterns were more stable during wet period than during dry period.

At $10 \mathrm{~cm}$ depth, location 35 can best represent the hillslope mean soil moisture under dry condition, while location 22 can be representative under intermediate and wet conditions. However, at $30 \mathrm{~cm}$ depth, location 60 can be representative under dry and intermediate conditions, while location 19 can be representative under wet condition. In addition, topography had dominant control on soil moisture temporal stability at each depth on study hillslope.

Acknowledgements. This study was financially supported by the National Natural Science Foundation of China (41571080 and 41801169), the Natural Science Foundation of Jiangsu Province (BK20180819), and the Natural Science Foundation of the Jiangsu Higher Education Institutions of China (18KJB170004). 


\section{REFERENCES}

[1] Baroni, G., Ortuani, B., Facchi, A., Gandolfi, C. (2013): The role of vegetation and soil properties on the spatio-temporal variability of the surface soil moisture in a maizecropped field. - Journal of Hydrology 489: 148-159.

[2] Brocca, L., Morbidelli, R., Melone, F., Moramarco, T. (2007): Soil moisture spatial variability in experimental areas of central Italy. - Journal of Hydrology 333(2-4): 356373.

[3] Brocca, L., Melone, F., Moramarco, T., Morbidelli, R. (2009): Soil moisture temporal stability over experimental areas in Central Italy. - Geoderma 148: 364-374.

[4] Brocca, L., Tullo, T., Melone, F., Moramarco, T., Morbidelli, R. (2012): Catchment scale soil moisture spatial-temporal variability. - Journal of Hydrology 422-423: 63-75.

[5] Budescu, D. V. (1993): Dominance analysis: a new approach to the problem of relative importance of predictors in multiple regression. - Psychological Bulletin 114: 542-551.

[6] Choi, M., Jacobs, J. M. (2010): Spatial soil moisture scaling structure during soil moisture experiment 2005. - Hydrological Processes 25: 926-932.

[7] Famiglietti, J. S., Rudnickim, J. W., Rodell, M. (1998): Variability in surface moisture content along a hillslope transect: Rattlesnake Hill, Texas. - Journal of Hydrology 210: 259-281.

[8] Famiglietti, J. S., Devereaux, J. A., Laymon, C. A., Tsegaye, T., Houser, P. R., Jackson, T. J., Graham, S. T., Rodell, M., van Oevelen, P. J. (1999): Ground-based investigation of soil moisture variability within remote sensing footprints during the Southern Great Plains 1997 (SGP97) Hydrology Experiment. - Water Resources Research 35: 1839-1851.

[9] Feng, H. H., Zou, B., Luo, J. H. (2017): Coverage-dependent amplifiers of vegetation change on global water cycle dynamics. - Journal of Hydrology 550: 220-229.

[10] Fu, B. J., Wang, J., Chen, L. D., Qiu, Y. (2003): The effects of land use on soil moisture variation in the Danangou catchment of the Loess Plateau, China. - Catena 54: 197-213.

[11] Gómez-Plaza, A., Alvarez-Rogel, J., Albaladejo, J., Castillo, V. (2000): Spatial patterns and temporal stability of soil moisture across a range of scales in a semiarid environment. - Hydrological Processes 14: 1261-1277.

[12] Grayson, R. B., Western, A. W., Chiew, F. H. S., Blöschl, G. (1997): Preferred states in spatial soil moisture patterns: local and nonlocal controls. - Water Resources Research 33(12): 2897-2908.

[13] Grayson, R. B., Western, A. W. (1998): Towards areal estimation of soil water content from point measurements: time and space stability of mean response. - Journal of Hydrology 207: 68-82.

[14] Hu, W., Shao, M., Han, F., Reichardt, K., Tan, J. (2010): Watershed scale temporal stability of soil water content. - Geoderma 158: 181-198.

[15] Hupet, F., Vanclooster, M. (2002): Interseasonal dynamics of soil moisture variability within a small agricultural maize cropped field. - Journal of Hydrology 261: 86-101.

[16] Jacobs, J. M., Mohanty, B. P., Hsu, E. C., Miller, D. (2004): SMEX02: field scale variability, time stability and similarity of soil moisture. - Remote Sensing of Environment 92: 436-446.

[17] Korres, W., Reichenau, T. G., Fiener, P., Koyama, C. N., Bogena, H. R., Cornelissen, T., Baatz, R., Herbst, M., Diekkrügere, B., Vereecken, H., Schneider, K. (2015): Spatiotemporal soil moisture patterns - A meta-analysis using plot to catchment scale data. Journal of Hydrology 520: 326-341.

[18] Laio, F., Porporato, A., Ridolfi, L., Rodriguez-Iturbe, I. (2002): On the seasonal dynamics of mean soil moisture. - Journal of Geophysical Research 107(D15): 4272.

[19] Lark, R. M. (1999): Soil-landform relationships at within-field scales: an investigation using continuous classification. - Geoderma 92: 141-165. 
[20] Li, D., Shao, M. (2014): Temporal stability of soil water storage in three landscapes in the middle reaches of the Heihe River, northwestern China. - Environmental Earth Sciences doi: 10.1007/s12665-014-3604-z.

[21] Liao, K., Lai, X., Liu, Y., Zhu, Q. (2016): Uncertainty analysis in near-surface soil moisture estimation on two typical land-use hillslopes. - Journal of Soils and Sediments doi: 10.1007/s11368-016-1405-6.

[22] Liao, K., Zhou, Z., Li, Y., Lai, X., Zhu, Q., Shan, N. (2018a): Comparison of seven water retention functions used for modelling soil hydraulic conductivity due to film flow. - Soil Use and Management 34: 370-379.

[23] Liao, K., Lai, X., Zhou, Z., Zhu, Q., Han, Q. (2018b): A simple and improved model for describing soil hydraulic properties from saturation to oven dryness. - Vadose Zone Journal 17: 180082. doi:10.2136/vzj2018.04.0082.

[24] Lin, H. (2006): Temporal stability of soil moisture patterns and subsurface preferential flow pathways in the Shale hills catchment. - Vadose Zone Journal 5: 317-340.

[25] Lv, L., Liao, K., Lai, X., Zhu, Q., Zhou, S. (2016): Hillslope soil moisture temporal stability under two contrasting land use types during different time periods. Environmental Earth Sciences 75: 1-12.

[26] Martínez-Fernández, J., Ceballos, A. (2003): Temporal stability of soil moisture in a large-field experiment in Spain. - Soil Science Society of America Journal 67: 1647-1656.

[27] McMillan, H., Srinivasan, M. S. (2015): Characteristics and controls of variability in surface and groundwaters in a headwater catchment. - Hydrology and Earth System Sciences 19: 1767-1786.

[28] Murray, K., Conner, M. M. (2009): Methods to quantify variable importance: implications for the analysis of noisy ecological data. - Ecology 90: 348-355.

[29] Norusis, J. M. (1994): SPSS professional statistics 6.1. SPSS Inc., Chicago, Ill.

[30] Nyberg, L. (1996): Spatial variability of soil water content in the covered catchment of Gardsjon, Sweden. - Hydrological Processes 10: 89-103.

[31] Pachepsky, Y., Radcliffe, D. E., Selim, H. M. (2003): Scaling Methods in Soil Physics. CRC Press, Boca Raton, FL.

[32] Penna, D., Brocca, L., Borga, M., Fontana, G. D. (2013): Soil moisture temporal stability at different depths on two alpine hillslopes during wet and dry periods. - Journal of Hydrology 477: 55-71.

[33] Qiu, Y., Fu, B., Wang, J., Chen, L. (2001): Spatial variability of soil moisture content and its relation to environmental indices in a semi-arid gully catchment of the Loess Plateau, China. - Journal of Arid Environments 49: 723-750.

[34] Qiu, Y., Fu, B., Wang, J., Chen, L. (2003): Spatiotemporal prediction of soil moisture content using multiple-linear regression in a small catchment of the Loess Plateau, China. - Catena 54: 173-195.

[35] Qiu, Y., Fu, B., Wang, J., Chen, L., Meng, Q., Zhang, Y. (2010): Spatial prediction of soil moisture content using multiple-linear regressions in a gully catchment of the Loess Plateau, China. - Journal of Arid Environments 74: 208-220.

[36] Qiu, Z. Y., Pennock, A., Giri, S., Trnka, C., Du, X., Wang, H. M. (2017): Assessing soil moisture patterns using a soil topographic index in a humid region. - Water Resources Management 31(6): 1-13.

[37] Schmidt, J. P., Beegle, D. B., Zhu, Q., Sripada, R. P. (2011): Improving in-season nitrogen recommendations for corn using an active sensor. - Field Crops Research 120: 94-101.

[38] Starks, P. J., Heathman, G. C., Jackson, T. J., Cosh, M. H. (2006): Temporal stability of soil moisture profile. - Journal of Hydrology 324: 400-411.

[39] Thierfelder, T. K., Grayson, R. B., van Rosen, D., Western, A. W. (2003): Inferring the location of catchment characteristic soil moisture monitoring sites, Covariance structures in the temporal domain. - Journal of Hydrology 280: 13-32. 
[40] Tromp-van Meerveld, H. J., McDonnell, J. J. (2006): Threshold relations in subsurface stromflow: 2. The fill and spill hypothesis. - Water Resources Research 42: W02411, doi: 10.1029/2004WR003800.

[41] Vachaud, G., Passerat de Silans, A., Balabanis, P., Vauclin, M. (1985): Temporal stability of spatially measured soil water probability density function. - Soil Science Society of America Journal 49: 822-828.

[42] van Arkel, Z. J. (2012): Using topographic and soils data to understand and predict field scale soil moisture patterns. - Master thesis, Iowa State University.

[43] Vereecken, H., Kamai, T., Harter, T., Kasteel, R., Hopmans, J., Vanderborght, J. (2007): Explaining soil moisture variability as a function of mean soil moisture: a stochastic unsaturated flow perspective. - Geophysical Research Letters 34: L22402, doi:10.1029/2007GL031813.

[44] Vivoni, E. R., Gebremichael, M., Watts, C. J., Bindlish, R., Jackson, T. J. (2008): Comparison of ground-based and remotely-sensed surface soil moisture estimates over complex terrain during SMEX04. - Remote Sensing of Environment 112: 314-325.

[45] Western, A. W., Grayson, R. B., Blöschl, G., Willgoose, G. R., McMahon, T. A. (1999): Observed spatial organization of soil moisture and its relation to terrain indices. - Water Resources Research 35: 797-810.

[46] Williams, C. J., McNamara, J. P., Chandler, D. G. (2009): Controls on the temporal and spatial variability of soil moisture in a mountainous landscape: the signature of snow and complex terrain. - Hydrology and Earth System Sciences 13: 1325-1336.

[47] Wu, C., Wu, J., Luo, Y., Zhang, L., DeGloria, S. D. (2009): Spatial prediction of soil organic matter content using cokriging with remotely sensed data. - Soil Science Society of America Journal 73: 1202-1208.

[48] Yates, S. R., Warrick, A. W. (1987): Estimating soil water content using cokriging. - Soil Science Society of America Journal 51: 23-30.

[49] Zhao, Y., Peth, S., Wang, X., Lin, H., Horn, R. (2010): Controls of surface soil moisture spatial patterns and their temporal stability in a semi-arid steppe. - Hydrological Processes 24: 2507-2519.

[50] Zhou, X., Lin, H., Zhu, Q. (2007): Temporal stability of soil moisture spatial variability at two scales and its implication for optimal field monitoring. - Hydrology \& Earth System Sciences Discussions 4: 1185-1214.

[51] Zhu, Q., Schmidt, J. P., Lin, H. S., Sripada, R. P. (2009): Hydropedological processes and implications for nitrogen availability to corn. - Geoderma 154: 111-122.

[52] Zhu, Q., Lin, H. S. (2011): Influences of soil, terrain, and crop growth on soil moisture variation from transect to farm scales. - Geoderma 163: 45-54.

[53] Zhu, Q., Zhou, Z. W., Duncan, E. W., Lv, L. G., Liao, K. H., Feng, H. H. (2017): Integrating real-time and manual monitored data to predict hillslope soil moisture dynamics with high spatio-temporal resolution using linear and non-linear models. Journal of Hydrology 545: 1-11. 